\title{
Opinião das Mulheres sobre as Circunstâncias em que os Hospitais Deveriam Fazer Abortos ${ }^{1}$
}

\author{
Women's Opinions on Circumstances Under Which Hospitals Should \\ Perform Abortions
}

\author{
Maria José Duarte Osis ${ }^{2}$; Ellen Hardy ${ }^{3}$; Anibal Faúndes ${ }^{3}$ \\ Graciana Alves ${ }^{2}$ \& Gunther Balarezo ${ }^{4}$
}
OSIS, M. F. D.; HARDY, E.; FAÚNDES, A.; ALVES, G. E BALAREZO, G. Women's Opinions on Circumstances Under Which Hospitals Should Perform Abortions. Cad. Saúde Públ., Rio de Faneiro, 10 (3): 320-330, Ful/Sep, 1994.

Little is known about the opinion of Brazilian women on induced abortion. One objective of a study carried out in the region of Campinas, São Paulo State, was to learn whether women agreed as to specific circumstances under which hospitals should provide abortions. A total of 1838 women of childbearing age and who had been pregnant at least once were interviewed. Single women and those who had had at least one induced abortion were the ones who most agreed with hospitals performing abortions under the circumstances presented. The circumstances most accepted were rape, the woman's life being at risk, and fetal malformation. A smaller percentage of women were in favor of abortion when the reasons affected the woman but could not be observed in a direct and objective way by others.

Key words: Abortion; Induced Abortion; Hospital-Performed Abortion; Women's Health

\section{INTRODUÇÃO}

O Código Penal (Brasil, 1940; Cook, 1991) em vigor no Brasil atualmente considera que 0 aborto é um crime. A pena prevista é de até três anos de reclusão, exceto se não houver outro meio para salvar a vida da gestante ou se a gravidez resultou de um estupro. Em qualquer destas circunstâncias o aborto deve ser consentido pela mulher ou, quando ela é incapaz, por seu representante legal (Art. 124 e 128).

Mesmo nos casos previstos na lei, o acesso

\footnotetext{
${ }^{1}$ A pesquisa da qual foram extraídos os dados apresentados neste trabalho foi realizada com financiamento da Fundação Ford.

${ }^{2}$ Centro de Pesquisa e Controle das Doenças MaternoInfantis. Caixa Postal 6181, Campinas, SP, 13081-970, Brasil.

${ }^{3}$ Departamento de Tocoginecologia da Universidade Estadual de Campinas. Caixa Postal 6181, Campinas, SP, 13081-970, Brasil.

${ }^{4}$ Instituto de Estudios de Población, Universidad Peruana Cayetano Heredia. Casilla Postal 4314, Lima, Peru.
}

ao aborto seguro é limitado. Há muita burocracia, em termos de exigências do poder judiciário, da polícia e dos médicos, para que uma mulher consiga interromper a gravidez na rede pública de saúde. No Estado de São Paulo, por exemplo, só existe um serviço de aborto legal, na capital (Andalaft-Neto, 1993). Apesar de todos esses problemas, há evidências de que 0 aborto é amplamente praticado no Brasil (Gardner, 1975; Frejka, 1988; Costa, 1993).

Esta situação contraditória tem levado, nos últimos anos, alguns setores da sociedade, tais como grupos organizados de mulheres e políticos ligados a partidos de esquerda, a trazerem $o$ assunto para uma discussão mais ampla, que possa resultar na alteração da legislação vigente. Neste momento, no âmbito do Ministério da Justiça, está atuando a Comissão para Elaboração do Anteprojeto de Reforma da Parte Especial do Código Penal. Logo, é oportuno o debate acerca do assunto porque se identifica uma possibilidade objetiva de mudar a lei. Organizações como o Conselho Estadual da Condição Feminina (CECF) de São Paulo e o 
Centro Feminista de Estudos e Assessoria (CFEMEA) de Brasília estão aproveitando a ocasião para mobilizar outros grupos, no sentido de pressionar a referida Comissão para que esta proponha mudanças significativas na legislação referente ao aborto (CECF, 1993; CFEMEA, 1993).

Porém, pouco se sabe a respeito da opinião que as mulheres, em geral, têm sobre a lei e que tipo de mudanças sugeririam. $\mathrm{O}$ que se tem feito comumente são os chamados estudos de opinião, realizados por diferentes meios de comunicação. Neles, em geral, apenas se pergunta se a mulher é contra ou a favor do aborto provocado.

As mulheres, entretanto, são as pessoas mais afetadas pela lei de aborto. Logo, é preciso conhecer com mais detalhes o que pensam a respeito, que sugestões gostariam de fazer, tendo em conta as possibilidades de mudanças. Este foi um aspecto abordado por um estudo realizado em 1992 em Campinas e Sumaré, estado de São Paulo. Este trabalho apresenta os resultados referentes à opinião de 1.838 mulheres sobre as circunstâncias em que os hospitais deveriam fazer abortos, segundo as diferentes características sociodemográficas, econômicas e reprodutivas das referidas entrevistadas.

\section{MATERIAL E MÉTODOS}

O objetivo principal da pesquisa foi estudar a freqüência e as condições em que era feito o aborto provocado no contexto de assistência integral à saúde da mulher. $\mathrm{O}$ desenho do estudo foi do tipo transversal-retrospectivo. O tamanho amostral foi calculado em 1.801 mulheres em idade fértil e que tiveram pelo menos uma gravidez. Este cálculo foi baseado em uma proporção de $25 \%$ de abortos provocados, estimados na população, com uma diferença de $2 \%$ entre a proporção populacional e amostral e com um intervalo de confiança de $95 \%$.

O trabalho de campo foi realizado em agosto de 1992. Utilizou-se um questionário estruturado com perguntas pré-codificadas e outras em que a resposta era anotada textualmente. Os dados foram obtidos através de entrevistas individuais, realizadas nos domicílios das mulheres selecionadas. Quando isto não era possível, marcava-se a entrevista para outro local.

Os domicílios visitados foram selecionados em setores censitários dos Municípios de Campinas e Sumaré, em que predominava a população de baixa renda, existindo favelas e cortiços. $\mathrm{Na}$ Delegacia do Instituto Brasileiro de Geografia e Estatística (FIBGE) de cada cidade foram obtidos mapas dos bairros que se pretendia trabalhar, com a correspondente divisão em setores. Cada entrevistadora recebia um setor por dia para realizar entrevistas. Em um de cada oito domicílios foram entrevistadas todas as mulheres com idade entre 15 e 49 anos e que residiam na casa. Não foram selecionadas as mulheres que estavam de visita ou de passagem. Posteriormente, foram excluídas do estudo as que nunca tinham estado grávidas. Ao final, 1.838 mulheres foram incluídas na pesquisa.

Para saber a opinião das entrevistadas sobre quando os hospitais deveriam fazer abortos, na última seção do questionário havia uma lista de circunstâncias, que eram lidas uma a uma para as mulheres, perguntando-se se elas achavam que os hospitais deveriam fazer abortos em cada uma das circunstâncias mencionadas.

Para o processamento e análise dos dados foi utilizado o Statistical Package for the Social Sciences (SPSS-PC). A diferença entre os grupos foi estudada com o teste qui-quadrado (Armitage, 1971). Para identificar os fatores associados à opinião favorável das mulheres a que os hospitais façam os abortos nas diversas circunstâncias foi feita análise por regressão logística (Hosmer \& Lemeshow, 1989), utilizando-se as seguintes variáveis:

\section{Independentes}

$\rightarrow$ Mulheres com aborto provocado ou que tomaram chá/remédio para descer a menstruação quando pensaram estar grávidas. $(\operatorname{sim}=1 /$ não $=0)$

$\rightarrow$ Idade da mulher na entrevista (anos)

$\rightarrow$ Escolaridade da mulher $(\mathrm{sem}=0 /$ mobral ou mais $=1)$

$\rightarrow$ Estado marital $($ sem companheiro $=0 /$ com companheiro $=1)$

$\rightarrow$ Trabalho remunerado $(\operatorname{sim}=1 /$ não $=0)$ 
$\rightarrow$ Número de filhos vivos

(até $2=0 / 3$ ou mais $=1$ )

$\rightarrow \operatorname{Cor}($ branca $=1 /$ outra $=0)$

\section{Dependentes}

(opiniões das mulheres sobre em que circunstâncias os hospitais deveriam fazer aborto)

Modelo 1 - A gravidez foi resultado de estupro Modelo 2 - Ficou grávida usando um anticoncepcional

Modelo 3 - A mulher tem doença grave e não vai resistir à gravidez

Modelo 4-A mulher trabalha, precisa do salário e será despedida se levar a gravidez até o fim

Modelo 5 - O feto tiver algum problema ou defeito grave

Modelo 6 - A mulher é solteira e o namorado sumiu depois dela ficar grávida

Modelo 7 - Quando a mulher achar que não tem condições financeiras de ter o filho

Modelo 8 - Quando a mulher achar que não tem condições psicológicas emocionais de ter o filho

Modelo 9 - A mulher não deseja o filho

\section{RESULTADOS}

As maiores proporções de opiniões favoráveis a que os hospitais façam abortos foram observadas nas circunstâncias de risco de vida para a mulher, estupro e malformação fetal. As menores se encontraram nas circunstâncias: sem condições econômicas, falha de método anticoncepcional (MAC), trabalho (a mulher poderá ser despedida se levar a gravidez até $o$ final) e mulher solteira - o namorado sumiu (Tabela 1).

A opinião favorável a que os hospitais façam abortos em caso de estupro variou significativamente com a escolaridade, o estado marital, $o$ trabalho remunerado e o número de filhos vivos na entrevista. Foram mais favoráveis as mulheres que tinham nível educacional superior, as solteiras, as que realizavam trabalho remunerado e as que tinham de um a dois filhos. Em caso de falha de MAC, as mulheres com nível educacional superior, as solteiras e com trabalho remunerado foram as que expressaram opinião mais favorável a que os hospitais façam abortos, sendo as diferenças estatisticamente significativas. Em se tratando de risco vida da mulher existiu variação significativa com o

TABELA 1. Mulheres que Referiram que os Hospitais Deveriam Fazer Abortos em Certas Circunstâncias (em percentagem)

\begin{tabular}{lcc}
\hline Circunstâncias & $\mathrm{N}$ & $\%$ \\
\hline Risco para a Mulher & 1417 & 77,1 \\
Estupro & 1128 & 61,4 \\
Malformação Fetal & 1082 & 58,9 \\
Sem Condições Psicológicas & 316 & 17,2 \\
Não Deseja Flho & 217 & 11,8 \\
Sem Condições Financeiras & 163 & 8,9 \\
Falha de Método & 159 & 8,7 \\
Trabalho & 129 & 7,0 \\
Mulher Solteira & 78 & 4,2 \\
Total de Mulheres & 1838 & \\
\hline
\end{tabular}

estado marital e a cor: entre as solteiras e as negras se observaram as maiores porcentagens de acordo com o aborto hospitalar (Tabela 2).

Apenas o estado marital se associou estatisticamente com opinião favorável ao aborto no caso da mulher trabalhar e poder ser despedida se levar a gravidez até o final, ou quando o feto tiver alguma malformação. A maior percentagem de acordo foi das solteiras e amasiadas. No caso da mulher grávida ser solteira, as mais favoráveis ao aborto hospitalar foram as entrevistadas que tinham nível educacional superior e as solteiras. Estas diferenças foram estatisticamente significativas (Tabela 3). 
TABELA 2. Mulheres que Referiram que os Hospitais Deveriam Fazer Abortos em Certas Circunstâncias, Segundo Algumas Características (em percentagem)

\begin{tabular}{|c|c|c|c|c|c|c|}
\hline \multirow{3}{*}{ Características } & \multicolumn{6}{|c|}{ Circunstâncias } \\
\hline & \multicolumn{2}{|c|}{ Estupro } & \multicolumn{2}{|c|}{ Falha MAC } & \multicolumn{2}{|c|}{ Risco para Mulher } \\
\hline & $\%$ & $\mathrm{~N}$ & $\%$ & $\mathrm{~N}$ & $\%$ & $\mathrm{~N}$ \\
\hline \multicolumn{7}{|l|}{ Idade } \\
\hline $15-19$ & 61,3 & 93 & 8,6 & 93 & 81,7 & 93 \\
\hline $20-24$ & 64,4 & 267 & 6,3 & 249 & 78,4 & 269 \\
\hline $25-29$ & 62,9 & 321 & 8,6 & 324 & 79,2 & 322 \\
\hline $30-34$ & 64,3 & 361 & 10,8 & 362 & 76,4 & 360 \\
\hline $35-39$ & 63,7 & 311 & 9,2 & 314 & 80,3 & 310 \\
\hline $40-44$ & 58,7 & 269 & 7,8 & 270 & 79,3 & 271 \\
\hline $45-49$ & 55,1 & 198 & 8,5 & 200 & 69,0 & 197 \\
\hline \multicolumn{7}{|l|}{ Escolaridade } \\
\hline $1^{\mathrm{a}}-4^{\mathrm{a}}$ série & 54,6 & *904 & 7,2 & *911 & 77,8 & 908 \\
\hline $5^{a}-8^{a}$ série & 70,4 & 585 & 8,4 & 586 & 78,3 & 581 \\
\hline $2^{\mathrm{a}}$ grau & 80,4 & 168 & 14,1 & 170 & 75,1 & 169 \\
\hline Superior & 89,1 & 46 & 23,4 & 47 & 89,4 & 47 \\
\hline \multicolumn{7}{|l|}{ Estado Marital } \\
\hline Solteira & 78,3 & ${ }^{\star *} 115$ & 17,4 & ${ }^{*} 115$ & 89,6 & ${ }^{\star \star} 115$ \\
\hline Casada & 60,5 & 1237 & 6,5 & 1247 & 75,2 & 1239 \\
\hline Amasiada & 60,3 & 297 & 11,1 & 298 & 81,5 & 297 \\
\hline Separada & 65,6 & 122 & 15,4 & 123 & 83,5 & 121 \\
\hline Viúva & 63,3 & 49 & 12,2 & 49 & 78,0 & 50 \\
\hline \multicolumn{7}{|l|}{ Trabalho } \\
\hline Remunerado & 65,9 & ${ }^{\star \star} 725$ & 10,3 & ${ }^{\star \star *} 726$ & 78,4 & 723 \\
\hline Sim & 59,3 & 1093 & 7,6 & 1104 & 77,4 & 1097 \\
\hline \multicolumn{7}{|l|}{ Não } \\
\hline \multicolumn{7}{|c|}{$\mathrm{N}$ de Filhos Vivos } \\
\hline Um & 68,6 & ${ }^{\star} 423$ & 9,4 & 425 & 79,0 & 424 \\
\hline Dois & 69,3 & 547 & 8,2 & 551 & 79,0 & 547 \\
\hline Três & 57,0 & 405 & 9,3 & 410 & 75,8 & 409 \\
\hline Quatro & 52,6 & 190 & 9,4 & 191 & 78,0 & 191 \\
\hline Cinco ou mais & 44,9 & 178 & 5,6 & 178 & 72,9 & 174 \\
\hline \multicolumn{7}{|l|}{ Cor } \\
\hline Branca & 62,7 & 1179 & 8,1 & 1189 & 76,2 & ${ }^{\star \star \star} 1182$ \\
\hline Negra/outras & 60,7 & 641 & 9,8 & 643 & 80,6 & 640 \\
\hline
\end{tabular}

$* \mathrm{p}<0,0003 ; * * \mathrm{p}<0,005 ; * * * \mathrm{p}<0,05$ 
TABELA3. Mulheres que Referiram que os Hospitais Deveriam Fazer Abortos em Certas Circunstâncias, Segundo Algumas Características (em percentagem)

\begin{tabular}{|c|c|c|c|c|c|c|}
\hline \multirow{3}{*}{ Características } & \multicolumn{6}{|c|}{ Circunstâncias } \\
\hline & \multicolumn{2}{|c|}{ Trabalho } & \multicolumn{2}{|c|}{ Malformação Fetal } & \multicolumn{2}{|c|}{ Mulher Solteira } \\
\hline & $\%$ & $\mathrm{~N}$ & $\%$ & $\mathrm{~N}$ & $\%$ & $\mathrm{~N}$ \\
\hline \multicolumn{7}{|l|}{ Idade } \\
\hline $15-19$ & 12,9 & 93 & 62,0 & 92 & 4,3 & 93 \\
\hline $20-24$ & 7,1 & 269 & 54,4 & 268 & 3,0 & 269 \\
\hline $25-29$ & 4,3 & 323 & 57,8 & 325 & 4,3 & 324 \\
\hline $30-34$ & 7,7 & 362 & 59,7 & 360 & 4,4 & 362 \\
\hline $35-39$ & 5,4 & 314 & 58,3 & 312 & 3,8 & 315 \\
\hline $40-44$ & 8,1 & 271 & 64,6 & 271 & 5,1 & 272 \\
\hline $45-49$ & 8,5 & 199 & 59,0 & 200 & 5,0 & 199 \\
\hline \multicolumn{7}{|l|}{ Escolaridade } \\
\hline $1^{\mathrm{a}}-4^{\mathrm{a}}$ série & 7,5 & 910 & 59,4 & 910 & 4,0 & ${ }^{\star} 913$ \\
\hline $5^{a}-8^{a}$ série & 5,5 & 586 & 59,1 & 584 & 3,1 & 586 \\
\hline $2^{\circ}$ grau & 7,6 & 170 & 58,8 & 170 & 5,9 & 170 \\
\hline Superior & 8,5 & 47 & 73,9 & 46 & 14,9 & 47 \\
\hline \multicolumn{7}{|l|}{ Estado Marital } \\
\hline Solteira & 15,7 & * 115 & 66,1 & ${ }^{\star \star} 115$ & 10,4 & ${ }^{\star \star \star} 115$ \\
\hline Casada & 5,4 & 1246 & 55,7 & 1242 & 3,0 & 1248 \\
\hline Amasiada & 8,7 & 298 & 67,4 & 298 & 5,7 & 298 \\
\hline Separada & 13,9 & 122 & 65,9 & 123 & 9,8 & 123 \\
\hline Viúva & 2,0 & 50 & 64,0 & 50 & & 50 \\
\hline \multicolumn{7}{|l|}{ Trabalho } \\
\hline Remunerado & 7,9 & 726 & 61,2 & 726 & 4,7 & 727 \\
\hline Sim & 6,5 & 1103 & 57,8 & 1100 & 4,0 & 1105 \\
\hline \multicolumn{7}{|l|}{ Não } \\
\hline \multicolumn{7}{|c|}{$\mathrm{N}^{\mathrm{o}}$ de Filhos Vivos } \\
\hline Um & 7,5 & 426 & 60,0 & 425 & 3,8 & 426 \\
\hline Dois & 6,4 & 549 & 59,7 & 549 & 3,5 & 550 \\
\hline Três & 7,1 & 411 & 59,0 & 410 & 5,1 & 412 \\
\hline Quatro & 6,8 & 191 & 58,1 & 191 & 5,2 & 191 \\
\hline Cinco ou mais & 6,7 & 177 & 53,6 & 177 & 3,9 & 178 \\
\hline \multicolumn{7}{|l|}{ Cor } \\
\hline Branca & 6,7 & 1187 & 58,6 & 1185 & 4,2 & 1190 \\
\hline Negra/outras & 7,6 & 644 & 60,2 & 643 & 4,3 & 644 \\
\hline
\end{tabular}

$* \mathrm{p}<0,003 ; * * \mathrm{p}<0,0006 ; * * * \mathrm{p}<0,0001$ 
$\mathrm{Na}$ circunstância da mulher não ter condições econômicas para ter ou criar o filho, encontrou-se uma variação estatística com 0 estado marital e a escolaridade, sendo as solteiras e as mulheres que tinham nível educacional superior as que mais se declararam favoráveis a que os hospitais realizem abortos. No caso da mulher não desejar ter o filho, os grupos que estiveram mais de acordo com o aborto hospitalar foram os das entrevistadas com nível educacional superior, das solteiras e das que tinham um filho (Tabela 4).

TABELA4. Mulheres que Referiram que os Hospitais Deveriam Fazer Abortos em Certas Circunstâncias, Segundo Algumas Características (em percentagem)

\begin{tabular}{|c|c|c|c|c|c|c|}
\hline \multirow{3}{*}{ Características } & \multicolumn{6}{|c|}{ Circunstâncias } \\
\hline & \multicolumn{2}{|c|}{$\begin{array}{l}\text { Sem Condições } \\
\text { Econômicas }\end{array}$} & \multicolumn{2}{|c|}{$\begin{array}{l}\text { Sem Condições } \\
\text { Emocionais }\end{array}$} & \multicolumn{2}{|c|}{$\begin{array}{l}\text { Não Deseja } \\
\text { Filho }\end{array}$} \\
\hline & $\%$ & $\mathrm{~N}$ & $\%$ & $\mathrm{~N}$ & $\%$ & $\mathrm{~N}$ \\
\hline \multicolumn{7}{|l|}{ Idade } \\
\hline $15-19$ & 12,2 & 93 & 17,2 & 93 & 19,4 & 93 \\
\hline $20-24$ & 8,2 & 269 & 14,9 & 268 & 13,4 & 268 \\
\hline $25-29$ & 9,2 & 325 & 18,2 & 325 & 11,4 & 325 \\
\hline $30-34$ & 8,6 & 362 & 15,0 & 361 & 10,3 & 360 \\
\hline $35-39$ & 6,0 & 315 & 17,1 & 315 & 12,1 & 313 \\
\hline $40-44$ & 11,4 & 272 & 22,1 & 272 & 12,1 & 272 \\
\hline $45-49$ & 9,0 & 200 & 16,6 & 199 & 9,2 & 196 \\
\hline \multicolumn{7}{|l|}{ Escolaridade } \\
\hline $1^{\mathrm{a}}-4^{\mathrm{a}}$ série & 8,6 & 914 & 19,0 & ${ }^{\star \star \star} 912$ & 16,1 & *909 \\
\hline $5^{a}-8^{a}$ série & 7,8 & 586 & 14,0 & 585 & 11,5 & 115 \\
\hline $2^{\circ} \mathrm{grau}$ & 10,5 & 171 & 14,6 & 171 & 17,0 & 171 \\
\hline Superior & 17,0 & 47 & 27,7 & 47 & 26,1 & 46 \\
\hline \multicolumn{7}{|l|}{ Estado Marital } \\
\hline Solteira & 20,9 & **115 & 28,7 & **115 & 28,7 & ** 115 \\
\hline Casada & 6,6 & 1250 & 14,5 & 1248 & 9,2 & 1243 \\
\hline Amasiada & 11,4 & 298 & 20,5 & 297 & 13,4 & 298 \\
\hline Separada & 14,6 & 123 & 25,2 & 123 & 18,7 & 123 \\
\hline Viúva & 8,0 & 50 & 20,0 & 50 & 14,6 & 48 \\
\hline \multicolumn{7}{|c|}{ Trabalho Remunerado } \\
\hline $\operatorname{Sim}$ & 9,6 & 728 & 16,6 & 728 & 13,4 & 725 \\
\hline Não & 8,4 & 1106 & 17,6 & 1103 & 10,9 & 1100 \\
\hline \multicolumn{7}{|c|}{$\mathrm{N}^{\mathrm{o}}$ de Filhos Vivos } \\
\hline $\mathrm{Um}$ & 8,9 & 426 & 16,7 & 425 & 15,1 & ${ }^{\star \star \star} 424$ \\
\hline Dois & 8,5 & 552 & 16,3 & 552 & 11,4 & 552 \\
\hline Três & 9,2 & 412 & 17,8 & 411 & 11,0 & 409 \\
\hline Quatro & 7,9 & 191 & 19,4 & 191 & 11,1 & 189 \\
\hline Cinco ou mais & 7,3 & 178 & 16,8 & 178 & 5,6 & 176 \\
\hline \multicolumn{7}{|l|}{ Cor } \\
\hline Branca & 8,4 & 1192 & 16,1 & 1191 & 11,9 & 1185 \\
\hline Negra/ou tras & 9,8 & 644 & 19,3 & 642 & 11,8 & 642 \\
\hline
\end{tabular}

${ }^{\star} \mathrm{p}<0,003 ;{ }^{\star \star} \mathrm{p}<0,0001 ;{ }^{\star \star \star} \mathrm{p}<0,03$ 
Encontrou-se variação significativa na opinião das mulheres sobre em quais circunstâncias os hospitais deveriam fazer abortos, segundo a história de aborto em sua vida. Apesar de existirem algumas variações segundo a circunstância proposta, houve um gradiente na opinião positiva ao aborto, sendo máxima entre as mulheres que já tinham feito um aborto provocado, seguidas por aquelas que não declararam nenhum mas tinham tomado chá ou remédio para "descer a menstruação" quando pensaram que estavam grávidas, e pelas que pensaram em abortar mas não chegaram a fazê-lo (Tabelas 5, 6 e 7).
As entrevistadas que nunca tinham feito nem pensado em fazer um aborto foram as menos favoráveis a que os hospitais realizem abortos quando a gravidez resulta de falha de MAC, implica risco para a mulher, esta seja solteira, possa ser despedida do trabalho, não tenha condições econômicas para ter o filho ou o feto apresente alguma malformação. Por sua vez, as mulheres que tiveram apenas abortos espontâneos foram as menos favoráveis no caso de estupro. Aquelas que, apesar de nunca terem feito um aborto, pensaram nisto, referiram com menor freqüência que os hospitais deveriam fazer abortos quando a mulher não deseja ter o filho (Tabelas 5, 6 e 7).

TABELA 5. Mulheres que Referiram que os Hospitais Deveriam Fazer Abortos em Certas Circunstâncias, Segundo História de Aborto (em percentagem)

\begin{tabular}{lcccccc}
\hline \hline & \multicolumn{6}{c}{ Circunstâncias } \\
\cline { 2 - 7 } & \multicolumn{2}{c}{ Estupro $^{\star}$} & \multicolumn{2}{c}{ Falha MAC $^{\star}$} & \multicolumn{2}{c}{ Risco para Mulher $^{\star}$} \\
\cline { 2 - 7 } História de Aborto & $\%$ & $\mathrm{~N}$ & $\%$ & $\mathrm{~N}$ & $\%$ & $\mathrm{~N}$ \\
\hline Nunca fez/nunca pensou & 62,1 & 1107 & 6,5 & 1113 & 75,9 & 1107 \\
Só teve aborto espontâneo & 55,3 & 405 & 7,3 & 411 & 76,1 & 410 \\
Nunca fez/pensou & 71,3 & 150 & 14,7 & 150 & 85,3 & 150 \\
Pensou estar grávida/ & & & & & & \\
Tomou chá ou remédio/ & & & & & & \\
menstruou & 63,9 & 83 & 19,3 & 83 & 85,0 & 80 \\
Fez aborto & 75,3 & 73 & 26,0 & 73 & 93,2 & 73 \\
\hline \hline
\end{tabular}

${ }^{\star} \mathrm{p}<0,0001$

TABELA 6. Mulheres que Referiram que os Hospitais Deveriam Fazer Abortos em Certas Circunstâncias, Segundo História de Aborto (em percentagem)

\begin{tabular}{lcccccc}
\hline \hline & \multicolumn{6}{c}{ Circunstâncias } \\
\cline { 2 - 7 } & \multicolumn{2}{c}{ Trabalho $^{*}$} & \multicolumn{2}{c}{ Malformação Fetal $^{\star \star}$} & Mulher Solteira $^{*}$ \\
\cline { 2 - 8 } História de Aborto & $\%$ & $\mathrm{~N}$ & $\%$ & $\mathrm{~N}$ & $\%$ & $\mathrm{~N}$ \\
\hline Nunca fez/nunca pensou & 5,1 & 1113 & 57,3 & 1112 & 2,6 & 1115 \\
Só teve aborto espontâneo & 5,8 & 411 & 57,6 & 408 & 2,7 & 411 \\
Nunca fez/pensou & 13,3 & 150 & 66,0 & 150 & 5,3 & 150 \\
Pensou estar grávida/ & & & & & & \\
Tomou chá ou remédio/ & & & & & & \\
menstruou & 15,7 & 83 & 66,3 & 83 & 15,7 & 83 \\
Fez aborto & 20,8 & 72 & 75,3 & 73 & 23,3 & 73 \\
\hline \hline
\end{tabular}

${ }^{\star} \mathrm{p}<0,0001 ;{ }^{\star \star} \mathrm{p}<0,005$ 
TABELA 7. Mulheres que Referiram que os Hospitais Deveriam Fazer Abortos em Certas Circunstâncias, Segundo História de Aborto (em percentagem)

\begin{tabular}{lcccccc}
\hline \hline & \multicolumn{5}{c}{ Circunstâncias } \\
\cline { 2 - 7 } & \multicolumn{2}{c}{$\begin{array}{c}\text { Sem Condições } \\
\text { Econômicas }\end{array}$} & $\begin{array}{c}\text { Sem Condições } \\
\text { Emocionais }^{*}\end{array}$ & \multicolumn{2}{c}{$\begin{array}{c}\text { Não Deseja } \\
\text { Filho* }^{*}\end{array}$} \\
\cline { 2 - 8 } História de Aborto & $\%$ & $\mathrm{~N}$ & $\%$ & $\mathrm{~N}$ & $\%$ & $\mathrm{~N}$ \\
\hline Nunca fez/nunca pensou & 6,8 & 1117 & 15,0 & 1115 & 11,0 & 1110 \\
Só teve aborto espontâneo & 7,3 & 411 & 16,5 & 411 & 9,0 & 410 \\
Nunca fez/pensou & 21,3 & 150 & 14,0 & 150 & 4,7 & 150 \\
Pensou estar grávida/ & & & & & & \\
Tomou chá ou remédio/ & & & & & & \\
menstruou & 25,3 & 83 & 27,7 & 83 & 22,0 & 82 \\
Fez aborto & 31,5 & 63 & 36,1 & 72 & 26,0 & 73 \\
\hline \hline
\end{tabular}

$\star p<0,0001$

A análise por regressão logística confirmou o que já se percebia na análise univariada. $\mathrm{O}$ fato de ter tido pelo menos um aborto provocado esteve associado à opinião favorável a que os hospitais façam abortos em todas as circunstâncias perguntadas, exceto quando a gravidez foi resultado de estupro. Nesse caso, as variáveis associadas foram o maior número de filhos vivos e o fato da mulher realizar algum trabalho remunerado. $\mathrm{O}$ maior número de filhos vivos também esteve associado a opinião favorável a que os hospitais façam o aborto quando a mulher não desejar o filho. $\mathrm{O}$ fato da mulher não ser branca esteve associado à opinião favorável ao aborto quando o prosseguimento da gravidez implicar risco de vida para a mulher (Tabela 8).

\section{DISCUSSÃO}

A opinião das mulheres sobre quais as situações em que os hospitais deveriam fazer abortos variou conforme suas características sociodemográficas e reprodutivas, como se esperava. É interessante salientar que, conforme o relato de algumas entrevistadoras, houve mulheres que fizeram questão de frisar que concordavam com que os hospitais fizessem abortos nas diferentes circunstâncias apresentadas desde que a mulher expressamente autorizasse esse ato.

As solteiras foram as mais favoráveis em todas as circunstâncias apresentadas. Isto é lógico, na medida que, ainda hoje, em nossa sociedade a mulher solteira que engravida é discriminada, enfrentando reprovação social e familiar, em especial. Dessa forma, como a maioria das situações sobre que se perguntou se relacionava ao contexto socioeconômico e cultural, era natural que esse grupo se mostrasse mais sensibilizado frente à questão do aborto.

A escolaridade também apareceu como um fator importante de influência na opinião das entrevistadas. $\mathrm{O}$ maior grau de instrução esteve associado a opiniões mais favoráveis na maioria das situações apresentadas. Isto pode ser entendido como um reflexo da educação formal sobre a maneira das pessoas encararem problemas sociais e existenciais, tornando-as, em parte, mais abertas a coisas novas, mais propensas a assumirem posturas mais liberais frente a questões polêmicas, como é o aborto provocado. Inversamente, também é possível pensar que mulheres com essas características são as que procuram por maior educação.

De modo geral, chama atenção que as circunstâncias em que as entrevistadas se manifestaram mais favoráveis a que os hospitais façam abortos foram aquelas já previstas na lei brasileira - estupro e risco de vida para a mulher - e aquela que atualmente se trata de incluir na legislação - a malformação fetal (CFEMEA, 1993). Isto leva a refletir sobre que outros fatores, além dos analisados neste trabalho, influenciariam a definição da postura das mulheres frente ao aborto provocado. 
TABELA 8. Variáveis Associadas a Opiniões Favoráveis a que os Hospitais Façam Aborto Segundo Circunstâncias que o Justificam

\begin{tabular}{|c|c|c|c|}
\hline Circunstância / Variáveis Associadas & Coeficiente & E.P. coef. & $\mathrm{p}$ \\
\hline \multicolumn{4}{|l|}{ 1. Estupro } \\
\hline - Número de filhos vivos & $-0,6629$ & 0,0988 & $<0,0001$ \\
\hline - Trabalho remunerado & 0,3054 & 0,1014 & 0,0026 \\
\hline - Constante & 0,6725 & 0,0764 & $<0,0001$ \\
\hline \multicolumn{4}{|l|}{ 2. Usando Anticoncepcional } \\
\hline $\begin{array}{l}\text { - Mulheres com aborto provoc. ou que } \\
\text { tomaram chá/remédio }\end{array}$ & 1,2800 & 0,2134 & $<0,0001$ \\
\hline - Constante & $-2,5204$ & 0,0933 & $<0,0001$ \\
\hline \multicolumn{4}{|l|}{ 3. Risco de Vida } \\
\hline $\begin{array}{l}\text { - Mulheres com aborto provoc. ou que } \\
\text { tomaram chá/remédio }\end{array}$ & 0,8550 & 0,2638 & 0,0012 \\
\hline - Cor & $-0,2556$ & 0,1222 & 0,0365 \\
\hline - Constante & 1,3732 & 0,1022 & $<0,0001$ \\
\hline \multicolumn{4}{|l|}{ 4. Trabalho } \\
\hline $\begin{array}{l}\text { - Mulheres com aborto provoc. ou que } \\
\text { tomaram chá/remédio }\end{array}$ & 1,2384 & 0,2328 & $<0,0001$ \\
\hline - Constante & $-2,7424$ & 0,1027 & $<0,0001$ \\
\hline \multicolumn{4}{|l|}{ 5. Malformação Fetal } \\
\hline $\begin{array}{l}\text { - Mulheres com aborto provoc. ou que } \\
\text { tomaram chá/remédio }\end{array}$ & 0,5328 & 0,1825 & 0,0035 \\
\hline - Constante & 0,3385 & 0,0498 & $<0,0001$ \\
\hline \multicolumn{4}{|l|}{ 6. Solteira } \\
\hline $\begin{array}{l}\text { - Mulheres com aborto provoc. ou que } \\
\text { tomaram chá/remédio }\end{array}$ & 2,0942 & 0,2506 & $<0,0001$ \\
\hline - Constante & $-3,5213$ & 0,1464 & $<0,0001$ \\
\hline \multicolumn{4}{|l|}{ 7. Sem Condições Econômicas } \\
\hline $\begin{array}{l}\text { - Mulheres com aborto provoc. ou que } \\
\text { tomaram chá/remédio }\end{array}$ & 1,6356 & 0,2017 & $<0,0001$ \\
\hline - Constante & $-2,5699$ & 0,0951 & $<0,0001$ \\
\hline \multicolumn{4}{|l|}{ 8. Sem Condições Emocionais } \\
\hline $\begin{array}{l}\text { - Mulheres com aborto provoc. ou que } \\
\text { tomaram chá/remédio }\end{array}$ & 0,8889 & 0,1852 & $<0,0001$ \\
\hline - Constante & $-1,6605$ & 0,0669 & $<0,0001$ \\
\hline \multicolumn{4}{|l|}{ 9. Não Deseja Filho } \\
\hline $\begin{array}{l}\text { - Mulheres com aborto provoc. ou que } \\
\text { tomaram chá/remédio }\end{array}$ & 0,9630 & 0,2050 & $<0,0001$ \\
\hline - Número de filhos vivos & $-0,3672$ & 0,1521 & 0,0157 \\
\hline - Constante & $-1,9657$ & 0,0955 & $<0,0001$ \\
\hline
\end{tabular}

\footnotetext{
- Mulheres com aborto provocado ou que - Número de filhos vivos tomaram chá/remédio $(\operatorname{sim}=1 /$ não $=0) . \quad($ até $2=0 / 3$ ou mais $=1)$

- Trabalho remunerado $(\operatorname{sim}=1 /$ não $=0) \quad$ - Cor $($ branca $=1 /$ outra $=0)$
} 
Uma tentativa de interpretação pode ser dada em termos de que, apesar de acharem que os hospitais devam fazer abortos nas diferentes situações inquiridas, as mulheres procuram respaldo social e moral para justificarem sua opinião. Houve maiores proporções de acordo justamente nas duas circunstâncias que já estão na lei e naquela em que se colocam questões a respeito das condições físicas e mentais de vida do futuro bebê, que seria o chamado aborto piedoso.

Porém, a porcentagem de acordo foi bem menor quando se tratou de circunstâncias em que a justificativa para o aborto seria de ordem mais subjetiva, por exemplo quando a mulher se declara sem condições psicológicas para ter e criar o filho, ou que não o quer; ou quando a gravidez pode ser interpretada como conseqüência de uma possível negligência da própria mulher, como no caso da falha de método.

Dentro do grupo de circunstâncias em que uma menor proporção de mulheres se mostrou favorável ao aborto nos hospitais, chama atenção que o não ter condições emocionais foi duas vezes mais aceito que o não ter condições econômicas ou possível perda do trabalho, indicando uma maior sensibilidade em relação ao que a mulher "sente" do que pelas condições materiais que deverá enfrentar.

Esses resultados fazem refletir ainda sobre a dificuldade que se tem para obter informações sinceras (honestas) das mulheres acerca do aborto provocado através da aplicação de questionários, da realização de entrevistas.

Primeiramente, porque qualquer inquérito desse tipo parece provocar nas pessoas que o respondem a sensação de estarem sendo julgadas. O fato de alguém se colocar na posição de quem quer respostas e a outra pessoa estar no lugar de quem deve responder, por si só estabelece uma relação de desigualdade, em que a parte mais fraca quase sempre fica com quem responde, sobretudo quando se trata de inquéritos feitos na população de mais baixa renda. $\mathrm{O}$ que se observa, em nossa experiência de pesquisa é que, em geral, existe a tendência dos entrevistados procurarem dar respostas que considerem adequadas à expectativa de quem está perguntando. É lícito, portanto, pensar que essa situação se agrava quando se trata de um tema como o aborto, cercado de tantos tabus e de tão intensa pressão social.

Existe uma perspectiva a respeito do aborto que é legitimada socialmente. A partir dela aceita-se como justificada a interrupção da gravidez nos casos previstos na lei, e quando se trate do chamado aborto piedoso que, curiosamente, apesar de não estar contemplado na lei, algumas vezes é tratado como se já estivesse ali mencionado. Refletindo sobre os resultados encontrados em nosso estudo verifica-se que esse conteúdo de legitimação social permeia totalmente a expressão daquilo que as mulheres afirmam ser a sua opinião. Pode-se pensar que grande parte das entrevistadas, mesmo inconscientemente, tenham tentado adequar sua opinião àquilo que imaginavam ser mais aceitável social e moralmente. Entretanto, quando se estudou a influência da história de aborto das mulheres sobre a sua opinião, ficou claro que o ter passado ou não pela experiência de ter provocado um aborto constituiu-se em um divisor de águas. As mulheres que já tinham passado por essa experiência, ou pensaram em fazê-lo, expressaram uma opinião mais favorável a que os hospitais façam aborto nas diversas circunstâncias, comparativamente às demais. Esse fato indica que a opinião expressa pelas mulheres quando requeridas sobre esse assunto sofre a influência de dois vetores: por um lado o consenso social sobre o que é moralmente correto em relação ao aborto, e por outro lado atua o ter passado por uma situação em que, ao menos, considerou-se a possibilidade de interromper a gravidez.

Esses resultados aqui discutidos colocam, portanto, a necessidade de uma postura crítica e criteriosa frente a possíveis plebiscitos acerca do aborto no Brasil. Se existe interesse genuíno de se adequar as leis à vontade das mulheres, que são as mais afetadas por esse problema, é necessário ter presente que qualquer inquérito sobre o assunto deve ser mais explícito e minucioso do que simplesmente perguntar: "você é contra ou a favor do aborto provocado?" Porque se assim for feito, esse inquérito terá como resultado previsível, com base em nossos achados, a vitória do contra, sem que isso possa ser considerado expressão do real pensamento 
das mulheres quanto o assunto. Logo, é preciso pensar-se em maneiras mais apropriadas para se obter com maior clareza e fidedignidade $o$ parecer das mulheres, e poder fazer mudanças significativas e eficazes na lei.

\section{RESUMO}

OSIS, M. J. D.; HARDY, E.; FAÚNDES, A.; ALVES, G. \& BALAREZO, G. Opinião das Mulheres sobre as Circunstâncias em que os Hospitais Deveriam Fazer Abortos. Cad. Saúde Públ., Rio de Janeiro, 10 (3): 320-330, jul/set, 1994.

Pouco se sabe a respeito da opinião que as mulheres brasileiras têm acerca do aborto provocado. Em um estudo realizado na região de Campinas, se quis conhecer, entre outras coisas, o que pensavam as mulheres sobre as circunstâncias em que os hospitais deveriam fazer abortos. Foram entrevistadas 1838 mulheres em idade fértil e que tinham engravidado pelo menos uma vez. Para saber se existiam algumas características das mulheres associadas à sua opinião, foi feita uma análise univariada, seguida por uma multivariada por regressão logística. As mulheres solteiras e as que haviam tido pelo menos um aborto provocado foram as que tiveram opinião mais favorável à realização de abortos pelos hospitais em todas as circunstâncias perguntadas. As

circunstâncias de estupro, risco de vida para a mulher e malformação fetal foram as que tiveram maior acordo. A proporção de mulheres que se manifestaram favoráveis foi menor no caso de aborto por razões que trazem conseqüências à mulher mas não podem ser observadas direta e objetivamente por outras pessoas.

Palavras-Chave: Aborto; Aborto Provocado; Aborto Hospitalar; Saúde da Mulher

\section{REFERÊNCIAS BIBLIOGRÁFICAS}

ANDALAFT-NETO, J., 1993. Responsabilidade Profissional/Ética na Atenção ao Aborto. Trabalho apresentado no Módulo sobre Aborto do Programa de Estudos em Saúde Sexual e Reprodutiva, abril de 1993. Campinas: Núcleo de Estudos da População da Universidade de Campinas/Centro de Pesquisas das Doenças Materno-Infantis de Campinas.

ARMITAGE, P., 1971. Statistical Methods in Medical Research. Oxford: Blackwell.

BRASIL, 1940. Decreto-Lei ${ }^{\circ}$ 2848, de 7 de dezembro de 1940.

CECF (Conselho Estadual da Condição Feminina), 1993. Circular $n^{\circ} 007 / 93$, São Paulo: CECF.

CFEMEA (Centro Feminista de Estudos e Assessoria), 1993a. Carta no 39/93, Brasília: CFEMEA. ,1993b. Pensando nossa Cidadania. Propostas para uma Legislação Não Discriminatória. Brasília: CFEMEA.

COOK, R., 1991. Leis e Políticas sobre o Aborto: Desafiose Oportunidades. São Paulo: Conselho Estadual da Condição Feminina.

COSTA, A. M., 1993. Direitos Reprodutivos: Riscos e Encruzilhadas. Trabalho apresentado no Módulo sobre Aborto do Programa de Estudos em Saúde Sexual e Reprodutiva, abril de 1993. Campinas: Núcleo de Estudos da População da Universidade de Campinas/ Centro de Pesquisa e Controle das Doenças Materno-Infantis de Campinas.

FREJKA, T., 1988. Programe for the Prevention and Reduction of Induced Abortions in Latin America and Caribbean. New York: Population Council.

GARDNER, R. F. R., 1975. Abortion, the Personal Dilemma. Exeter Devon: Paternoster Press Ltd.

HOSMER, D. W. \& LEMESHOW, S., 1989. Applied Ligistic Regression. New York: John Wiley \& Sons. 